\title{
Prediction of Indoor Radon Concentration through the Exhalation from Korean Yellow Residual Soil, Hwangtoh as a Building Material ${ }^{1}$
}

\author{
$\mathrm{Ju}$ Yong $\mathrm{LEE}^{2} \cdot \operatorname{Seog}$ Goo $\mathrm{KANG} \mathbb{D}^{3, \dagger}$
}

\begin{abstract}
The radon gas from nature mainly considers a cause of radon problems, and it is closely affect human life cycle. Korean yellow residual soil, Hwangtoh, widely used as a building material, is considered to be one of major sources of indoor radon. However, there have, as yet, been no studies about radon from Hwangtoh in mass market brands. Here, we investigated the indoor radon concentrations and exhalation rates in four Hwangtohs from different brand names and regional features. The Closed Chamber Method (CCM) conducted by a Continuous Radon Monitor (CRM) has been used for the rates of radon exhalation. Based on equations of previous references, the indoor radon concentrations were deducted. As a result, the radon surface exhalation rates resulted in the 1.4208 to $3.0293 \mathrm{~Bq} \cdot \mathrm{m}^{2} \cdot \mathrm{h}^{-1}$ range. Significant differences were found among Hwangtohs according to production regions. Materials with higher radon concentration required a longer time to reach a quasi-steady state in a given environment, in other words, the number of half-life cycles increased from a set starting point. The experimentally identified Hwangtohs demonstrated its safety for construction purposes. There exists, so far, a possibility to exert influence radon emanation due to unidentified factors. Therefore, it is necessary to corroborate with more research by increasing the number of Hwangtohs, considering the other references reported high radon exhalation rates. In addition, it is highly recommended that the radon exhalation rates should be measured for all building materials for preventing human health before the material usage.
\end{abstract}

Keywords: closed chamber method (ccm), indoor radon, exhalation rate, hwangtoh, yellow residual soils, building materials

\section{INTRODUCTION}

Modern people are exposed to indoor pollutants as the indoor living time increases (Lee, et al., 2014). Indoor air pollutants include building materials, vola- tile organic compounds (VOCs) such as formaldehyde, and naturally occurring gases like radon, and there has been an increasing interest in eco-friendly building materials that do not release volatile organic compounds (Han, et al., 2019; Jang, et al., 2017; Jang,

\footnotetext{
${ }^{1}$ Date Received October 5, 2020, Date Accepted February 3, 2021

2 Department of Civil and Environmental Engineering, College of Engineering, KAIST, Daejeon 34141, South Korea

${ }^{3}$ Department of Department of Biobased Materials, College of Agriculture \& Life Science, Chungnam National University, Daejeon 34134, South Korea

† Corresponding author: Seog Goo KANG (e-mail: lachesis@cnu.ac.kr, ORCID: 0000-0002-2440-7070)
} 
et al., 2017; Choi, et al., 2020; Park, et al., 2020). Radon, as an indoor air pollutant, is unintentionally exposed because it is difficult to determine the degree of contamination (Kim, 2018).

Radon $\left({ }^{222} \mathrm{Rn}\right)$ is one of the carcinogenic, invisible, and odorless gases usually found in environments on earth. Radon with no stable isotopes has been discovered in about 40 isotopes with different atomic masses between 193 and 231 (Neidherr et al., 2009). ${ }^{222} \mathrm{Rn}$, the most stable isotope having 3.82 days halflife, is produced by decaying radium $\left({ }^{226} \mathrm{Ra}\right)$ and uranium $\left({ }^{238} \mathrm{U}\right)$ (Elliot et al., 2014; Singh et al., 2005). This gas spreads easily from sources such as the ground to air in the room (Faheem and Matiullah, 2008, Parajuli et al., 2015), and dissolves quickly into ground water. People are easily exposed to the radon gas and lead serious consequences such as lung cancer.

Previous studies noted that exposure to indoor radon gas is causative of critical health influence such as lung cancer (Lubin et al., 1995). Since the International Agency for Research on Cancer (IARC) declared exposing radon consisted of about $14 \%$ is one of major contributors of lung cancer (IARC, 1988). The relationship between radon and lung cancer has been heightened that radon is considered as the first hazard factor for non-smokers (EPA, 2012). However, the influence of radon has not yet been fully understood. According to case studies by the WHO handbook in 2009 , the possibility of having lung cancer grows up to $16 \%$ per $100 \mathrm{~Bq} / \mathrm{m}^{3}$ with exposure of the average concentration during a long period (Zeeb et al., 2009). The proportional correlation, as an example, is denoted between exposure to radon and lung cancer. The increase in time of exposure and of radon concentration augment the development of cancer (Lubin and Boice, 1997; Webb, 1992). These examples show that indoor radon presence is harmful and threatens the health of residents.

While the importance of the health impact of radon has emerged, the International Commission for Radiological Protection (ICRP) defined a terminology of radon prone areas where radon concentration in building is higher than national average to inform of the danger and to save people from high perpetual exposure, where $1 \%$ or higher of buildings in the United States occupy higher indoor radon concentration, which is 10 times higher than the average (ICRP, 1993). Similarly, scientists reported the harmful effects of radon since 1976, radon issue has been started in the spotlight from last couple years in Republic of Korea. In 2018, the Korean broadcast reported a large quantity of radon was detected in beds, mattresses, pillows, and even sanitary pads. Knowing the relationship between radon and cancer made an influence people's safeties and behaviors, and it led people to raise awareness about radon. Building materials are closely connected with radon concentration in households because radon exhalation occurred from every building material people use. Building materials, such as soil and rocks, are considered one of the major contributors of radon.

The yellowish-reddish brown residual soil, called Hwangtoh in Korea, produced by the weathering of parent rocks not only have been used as a major building material for the Korean traditional houses since ancient times, but also have been widely used for all sorts of applications. Hwangtoh is used as cosmetics, beds, red tide reduction (Seok and Jun, 2009), animal feeding (Hwang et al., 2002), foods, naturally dyed clothing (Rhie and Choi, 2005), natural pigment (Mun et al., 2019), accumulation of heavy metals (Jeong and Kim, 1990; Shin et al., 2011) as well as various health-products today. Hwangtoh is also used as an interior building material for Korean-style decorations of the wall, ceiling and floor of modern apartments (Kim et al., 2010). Hwangtoh is comprised of diverse clay minerals such as illite, micas/vermiculite, and kaolinite (Hwang and Lee, 2010). Due to soil properties, the particle size is distinction among their color, 
density, mineral, chemical compositions, and even differences of microorganism communities. For example, the increase of iron oxide in the soil, Hwangtoh, become more reddish color and higher density as the particle size decreased. Soil colors are also changeable to different color such as gray when it turns anaerobic because of the different microorganisms' growths.

Hwangtoh has many advantages as a building material, such as excellent insulation properties, regulation of temperature and humidity (Kim et al., 2010), good acoustic environment, air permeability, durability, recyclability, versatility, and deodorization (Kim et al., 2000). It has been known for many years about significant health benefits because it prevented mould growth in the home. All of these create a superior internal air quality which is closely related to human health. In spite of these advantages, radon found in several products has attracted public attention today. Researchers reported a warning about the radon from soil, and maintained the soil is one of main sources of high radon emission (Parajuli et al., 2015; Seo et al., 2018; UNSCEAR, 2000; Yoo et al., 2019). Korean traditional residual soil, Hwangtoh, has been seriously influenced by these even though the information is not directly mentioned about Hwangtoh. It is no longer available to use rare earth elements and yellow residual soil as bedding such as mattresses and pillows for the intention of health improvement until a reliable media announces its safety. So far, the Korea Institute of Nuclear Safety (KINS) has organized the assessment of radon concentration levels within various houses in South Korea. The radon concentration in structures built by ochre, wood, concrete, and prefabricated materials are $74.1 \mathrm{~Bq} \cdot \mathrm{m}^{-3}, 54.9 \mathrm{~Bq} \cdot \mathrm{m}^{-3}, 53.1$ $\mathrm{Bq} \cdot \mathrm{m}^{-3}$, and $36.6 \mathrm{~Bq} \cdot \mathrm{m}^{-3}$, respectively. The hazard indexes of Hwangtoh and Hwangtoh brick represent 0.83 and 0.74 , respectively, which ranked the third and fourth highest among 12 building materials (Kim et $a l, 2002)$. However, they analyzed only one Hwangtoh sample, and it is unable to produce statistically significant and reliable results in this case.

Radon exhalation from soil depends on various factors such as its radium content, permeability, mineralogy, water content, water filled pore space, and particle size through parent rock and soil (Gundersen and Schumann, 1996; UNSCEAR, 2000). Building materials based on soil are often considered as one of the major sources of indoor radon because radon is shaped predominantly in the soil and rock. Given these emerging issues, there have, as yet, been no studies about radon exhalation from Hwangtoh in mass market brands. Therefore, it is of interest to the Korean public to evaluate Hwangtoh's radon contribution, and it is commonly available in Korean markets, and to verify whether Hwangtoh used in building materials at Korean homes have any difference in radon emanation properties. Herein, this research aims to address this public safety issue about radon from Hwangtoh, to assess indoor radon levels in the contribution of Hwangtoh in accordance with the different production areas in Korean Hwangtoh markets, to rectify the misunderstanding about Hwangtoh, and specifically to estimate indoor radon concentration from the radon exhalation rate of Hwangtoh samples by the Closed Chamber Method (CCM).

\section{MATERIALS and METHODS}

\subsection{Hwangtoh samples}

Radon exhalations of four different brands of residual yellow soils (Hwangtoh), commonly known as red clay or ocher, were measured in this study. The soils were easily accessible and inexpensive, and they were purchased at Korean markets under different soil brand names based on different regional features of raw materials. The soils were selected from the four 


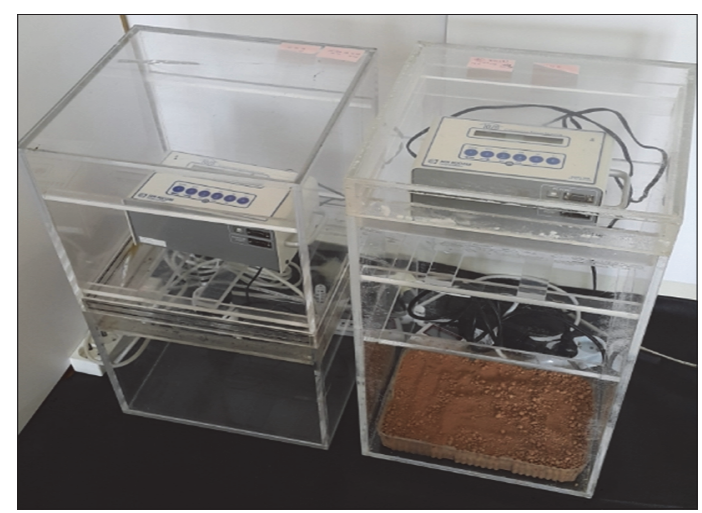

Fig. 1(a). Self-designed closed chambers.

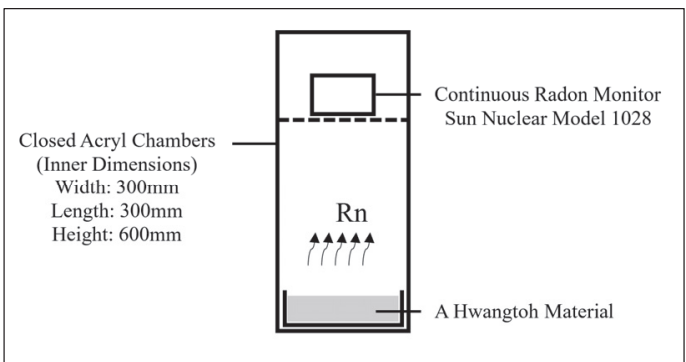

Fig. 1(b). Scheme of the experiment in the CCM.

provinces in South Korea. After samples were dried in oven at $105{ }^{\circ} \mathrm{C}$ for $24 \mathrm{~h}$ to evaporate all moisture contents, the samples were cooled at room temperature for $24 \mathrm{~h}$ to get moisture contents in air. After cooling, $2 \mathrm{~kg}$ of each sample was placed in plastic vessels with a sample surface area of $0.28 \mathrm{~m} \times 0.2 \mathrm{~m}, 0.056 \mathrm{~m}^{2}$ as shown in Fig. 1(a) and 1(b).

\subsection{Experimental process}

The general experimental process followed by CCM. Without this method, it is difficult to know what exact percent of gas is in air. To measure accurate radon exhalations of samples, the CCM required because gathering a specific gas in a blocked space is easier for calculating accurate gas concentration (Petropoulos et al., 2001). This procedure is described well in a previous paper (Lee et al., 2018). Briefly, self-designed acryl chambers (width: $300 \mathrm{~mm}$, length: $300 \mathrm{~mm}$, height: $600 \mathrm{~mm}$, volume: $0.054 \mathrm{~m}^{2}$ ) were created and hermetically sealed. Two continuous radon monitors, Sun Nuclear Model 1028, were used for the whole experiment. High resolution data of the radon concentration can be achieved to the CRM, Model 1028 (Sun Nuclear Co., USA), over time. As shown in Fig. 1(a) and 1(b), a sample, Hwangtoh, was laid on the floor, and the machine was installed over the sample, which was $30 \mathrm{~cm}$ away from the radon monitor. Radon gas was detected continuously over 12 points a day for 20 days after the points reached a stable level within fifth half-lives. Temperature and humidity were indicated to $26 \pm 2{ }^{\circ} \mathrm{C}$ and RH $55 \pm 3 \%$, respectively. For the blank, a chamber without samples was prepared and measured with the same procedure to figure out where radon emission was actually coming from and to get rid of the background effect.

\subsection{Calculation of radon emanation}

According to the Petropoulos article, enclosed sample method is the most general technique to measure the exhalation rate of a typical building material (Petropoulos et al., 2001). A sample is in a closed container, and the increasing amount of the radon concentration in the air volume is described by the following equation:

$$
\mathrm{C}=\mathrm{C}_{\mathrm{o}} \cdot e^{-\lambda t}+E\left(1-e^{-\lambda t}\right)(\lambda V)^{-1}
$$

$$
\begin{aligned}
& \text { where: } \\
& \mathrm{C}=\text { sample's radon concentration }\left(\mathrm{Bqm}^{-3}\right) \text { in a container } \\
& \text { at growth time } \mathrm{t}(\mathrm{h}) \\
& \mathrm{E}=\text { exhalation rate of radon }\left(\mathrm{Bqh}^{-1}\right) \\
& \lambda=\text { decay constant of radon }\left(\mathrm{h}^{-1}\right) \\
& \mathrm{C}_{\mathrm{o}}=\text { initial concentration of radon }\left(\mathrm{Bqh}^{-1}\right) \text { in a container } \\
& \text { at the initial time } t_{0} \\
& \mathrm{t}=\text { time in measurement }
\end{aligned}
$$

From the equation (1), the conversion of radon ex- 
halation from the measured data was calculated, and it could be directly transformed to equation (2) by Chen (Chen et al., 2010).

$$
\mathrm{C}=\mathrm{E} \cdot \mathrm{A}\left(1-e^{-\lambda t}\right)(\lambda V)^{-1}+\mathrm{C}_{\mathrm{o}} \cdot e^{-\lambda t}
$$

where:

$$
\begin{aligned}
& \mathrm{A}=\text { surface area of sample }\left(\mathrm{m}^{2}\right) \\
& \mathrm{V}=\text { enclosing volume of the chamber }\left(\mathrm{m}^{3}\right)
\end{aligned}
$$

When applying equation (2), the surface exhalation rate in the air tighten container should be similar to the free surface exhalation in accordance with the actual room condition.

$$
\mathrm{C}(\mathrm{t})=\mathrm{E} \cdot \mathrm{A}\left(1-e^{-\lambda_{e f f} t}\right)\left(\lambda_{e f f} V\right)^{-1}
$$

where:

$\lambda_{\text {eff }}=\lambda+\lambda_{b}+\lambda_{\text {leak }}\left(\mathrm{s}^{-1}\right)$, which consists of decay constant, back-diffusion coefficient and chamber leakage coefficient, respectively.

For equation (3) by Awhida (Awhida et al., 2016), the measurement can be compared with the standard accumulation method with the same geometry and its free surface. Equation (3) is combined to the concept of measurement time. When applying Equation (2), it is necessary to minimize the background term, $\mathrm{C}_{\mathrm{o}}$, especially for materials of low radon exhalation rates. Chen reported that the contribution from the term $\mathrm{C}_{0} \cdot e^{-\lambda t}$ in Equation (2) could be neglected in the case of the radon concentration in the laboratory where all testing was performed was under $15 \pm 10 \mathrm{Bqm}^{-3}$. Therefore, the Equation (2) can be transformed to the Equation (4) if the both values, the compensating and neglecting expressions, $\mathrm{C}_{\mathrm{o}} \cdot e^{-\lambda t}$, are negligible.

$$
\begin{aligned}
E_{A} & =\mathrm{C} \lambda V\left[A\left(1-e^{-\lambda t}\right)\right]^{-1} \\
E_{M} & =\mathrm{C} \lambda V\left[M\left(1-e^{-\lambda t}\right)\right]^{-1}
\end{aligned}
$$

Where:

$\mathrm{E}_{\mathrm{M}}=$ mass exhalation rate $(\mathrm{Bq} / \mathrm{kg} \cdot \mathrm{h})$

$\mathrm{E}_{\mathrm{A}}=$ areal exhalation rate $\left(\mathrm{Bq} / \mathrm{m}^{2} \mathrm{~h}\right)$

$\mathrm{M}=$ mass of sample $(\mathrm{kg})$

Based on the all four calculations, the verification measurement values can be confirmed and transferred to the meaningful values of radon emanation.

\subsection{Prediction of indoor radon concentration}

Indoor radon concentration was estimated from the radon exhalation rate of Hwangtoh samples calculated by Equation (4). The contribution of indoor radon concentration from the exhalation rate of Hwangtoh samples can be calculated with the following Equation (5) (Lee et al., 2018; Mahur et al., 2009; Nazaroff and Nero, 1988).

$$
C_{R n}=\frac{E_{x} S_{r}}{V_{r} \lambda_{v}}
$$

Where:

$\mathrm{C}_{R n}=$ concentration of indoor radon emanation from building materials $\left(\mathrm{Bq} / \mathrm{m}^{3}\right)$

$\mathrm{E}_{x}=$ exhalation rate of radon $\left(\mathrm{Bq} \cdot \mathrm{m}^{-2} \cdot \mathrm{h}^{-1}\right)$

$\mathrm{V}_{r}=$ Volume of the room $\left(\mathrm{m}^{3}\right)$

$\lambda_{v}=$ air-exchange rate $(\mathrm{ach})$

$\mathrm{S}_{r}=$ Surface area $\left(\mathrm{m}^{2}\right)$

\subsection{Exhalation rate analysis}

The results are demonstrated from the measured values of Hwangtoh as a building material from the continuous radon monitor to verify the characteristics of radon concentration. The recorded data and the curves of the results were processed using statistical analysis, which were operated by IBM SPSS version 22 because the tendency cannot be proved with only the result curves. The properties of Hwangtoh in different production regions over the half-life can be determined by measuring 230 radon counts. 


\section{RESULTS and DISCUSSION}

\subsection{Radon exhalation rate over Korean residual soil, Hwangtoh}

The concentrations of exhalation of all the tested Hwangtohs were measured to be distributed across the range between 5.3 and $11.3 \mathrm{pCi} / \mathrm{L}$ in a chamber as shown in Table 1. The mass exhalation rates of all the samples were calculated, which ranged from 0.0398 to $0.0848 \mathrm{~Bq} \cdot \mathrm{kg}^{-1} \cdot \mathrm{h}^{-1}$. Moreover, the surface exhalation rates resulted in the $1.4208-3.0293 \mathrm{~Bq} \cdot \mathrm{m}^{2} \cdot \mathrm{h}^{-1}$ range. The result shows that the surface and mass exhalation rates are significant over the production areas. Although D Province Hwangtoh is the highest value among the samples, it is still below the world average, $57.6 \mathrm{~Bq} \cdot \mathrm{m}^{-2} \cdot \mathrm{h}^{-1}$ in Table 2 (UNSCEAR, 2000).

The correcting backgrounds by a control were not performed, well described in a previous paper (Lee et al., 2018). In brief, the correcting values were not effective to process every single counts, 230 counts, of samples and a blank. Because of this treatment, the statistical significance test for group differences for radon exhalations from Hwangtohs along with production regions was conducted without the corrected background effect as shown in Table 3. Because the control corrections of empty chambers had shown a similar aspect, the distribution for the statistical significance tests indicates the same result whether each exhalation rate of Hwangtoh is corrected or not by the blanks.

As a result of the statistical data, four Hwangtoh materials were divided into three groups: $\mathrm{C}$ and $\mathrm{A}<\mathrm{B}<$ D. Significant differences were found among Hwangtoh materials according to the production regions. The regional differences are probably caused by physicochemical differences and climate-controlled differences in soil

Table 1. Radon Concentration, Surface Exhalation Rate and Mass Exhalation Rate for Hwangtohs

\begin{tabular}{cccccc}
\hline Production area & $\begin{array}{c}\text { Overall Avg. in } \\
\text { chamber }(\mathrm{pCi} / \mathrm{L})\end{array}$ & $\begin{array}{c}\text { Empty chamber } \\
(\mathrm{pCi} / \mathrm{L})\end{array}$ & $\begin{array}{c}\text { Concentration of } \\
\text { emanation }(\mathrm{pCi} / \mathrm{L})\end{array}$ & $\begin{array}{c}\text { Surface exhalation } \\
\text { rate }\left(\mathrm{Bq} \cdot \mathrm{m}^{-2} \cdot \mathrm{h}^{-1}\right)\end{array}$ & $\begin{array}{c}\text { Mass exhalation rate } \\
\left(\mathrm{Bq} \cdot \mathrm{kg}^{-1} \cdot \mathrm{h}^{-1}\right)\end{array}$ \\
\hline \hline A Province & 6.3 & 0.4 & 5.9 & 1.5817 & 0.0443 \\
B Province & 7.2 & 0.4 & 6.8 & 1.8230 & 0.0510 \\
C Province & 5.7 & 0.4 & 5.3 & 1.4208 & 0.0398 \\
D Province & 11.7 & 0.4 & 11.3 & 3.0293 & 0.0848 \\
\hline
\end{tabular}

Table 2. Radon Exhalation Rates of Soils from Various References

\begin{tabular}{|c|c|c|c|c|}
\hline Material & $\begin{array}{c}\text { Radon exhalation } \\
\text { per unit area }\left(\mathrm{Bq} \cdot \mathrm{m}^{-2} \cdot \mathrm{h}^{-1}\right)\end{array}$ & $\begin{array}{c}\text { Radon exhalation } \\
\text { per unit weight }\left(\mathrm{Bq} \cdot \mathrm{kg} \cdot \mathrm{h}^{-1}\right)\end{array}$ & $\begin{array}{l}\text { Countries } \\
\text { origin }\end{array}$ & Reference \\
\hline Soil & - & 0.0777 & U.S.A. (CA,MD) & (Ingersoll, 1983) \\
\hline Soil & 57.6 & - & World average & (UNSCEAR, 1969) \\
\hline Soil & $0.375 \pm 0.147$ & - & Pakistan(Punjab) & (Faheem and Matiullah, 2008) \\
\hline Soil & $72-7560$ & - & Syria & (Shweikani and Hushari, 2005) \\
\hline Soil & $0.246-1.100$ & - & India & (Singh et al., 2005) \\
\hline Soil & - & $0.0391-0.0912$ & India & (Bala et al., 2017) \\
\hline Soil & $0.003-0.145$ & - & Morocco & (Oufni, 2003) \\
\hline Soil & $0.4368-2.7913$ & $0.00219-0.01403$ & Nepal & (Parajuli et al., 2015) \\
\hline Soil & $161.28-174.96$ & - & South Korea & (Seo et al., 2018) \\
\hline Hwangtoh & $1.421-3.029$ & $0.040-0.085$ & South Korea & Present study \\
\hline
\end{tabular}


Table 3. Group Differences of Radon Exhalations from Hwangtohs along with Production Regions

\begin{tabular}{|c|c|c|c|c|c|c|}
\hline Production region & $\begin{array}{c}\text { Overall Avg. } \\
\text { in chamber. }(\mathrm{pCi} / \mathrm{L})\end{array}$ & Total mean \pm SD & $\begin{array}{l}\text { Min } \\
\operatorname{Max}\end{array}$ & F-test & P-Value & $\begin{array}{c}\text { Group } \\
\text { difference }\end{array}$ \\
\hline A Province & $6.3(\mathrm{~A})$ & $6.2539 \pm 2.3031$ & $\begin{array}{c}.00 \\
11.00\end{array}$ & \multirow{4}{*}{198.514} & \multirow{4}{*}{.000} & \multirow{4}{*}{$\mathrm{C}, \mathrm{A}<\mathrm{B}<\mathrm{D}$} \\
\hline B Province & 7.2 (B) & $7.2057 \pm 2.5644$ & $\begin{array}{c}.40 \\
12.10\end{array}$ & & & \\
\hline C Province & $5.7(\mathrm{C})$ & $5.7409 \pm 2.1216$ & $\begin{array}{c}.60 \\
11.00\end{array}$ & & & \\
\hline D Province & 11.7 (D) & $11.672 \pm 4.1794$ & $\begin{array}{c}.40 \\
19.00 \\
\end{array}$ & & & \\
\hline Total & 7.7 & $7.7180 \pm 3.7319$ & $\begin{array}{c}.00 \\
19.00\end{array}$ & & & \\
\hline
\end{tabular}

weathering and parent rocks (UNSCEAR, 1969). Hence it is concluded that these Hwangtoh materials in this study are available to use for construction purposes until due to low exhalation of radon, which is lower than both the Korean radon recommendation level, 200 $\mathrm{Bq} / \mathrm{m}^{3}$ and WHO's action level, $100 \mathrm{~Bq} / \mathrm{m}^{3}$.

\subsection{Conversion to indoor radon concentration}

Every country has different acceptable indoor radon levels. A common action level, $100 \mathrm{~Bq} / \mathrm{m}^{3}$ or $2.7 \mathrm{pCi} / \mathrm{L}$, was established by the WHO (Zeeb et al., 2009). In the United States, the Environmental Protection Agency noted that the action level of $148 \mathrm{~Bq} / \mathrm{m}^{3}$ (4 pCi/L) is the standard (EPA, 2012). In South Korea, the Ministry of Environment drew up guidelines for the radon standard level, $148 \mathrm{~Bq} / \mathrm{m}^{3}$ for multi-use facilities and 200 $\mathrm{Bq} / \mathrm{m}^{3}$ for new apartment houses since 2018, two times higher than that of the WHO (KME, 2016).

On the basis of the findings, one can estimate the contribution of the radon emanating from the Hwangtoh materials used in a typical Korean house to its indoor radon levels. From Equation (5), the results of the radon concentrations in the closed chambers can be applied and predicted to a hypothetical space as a general building. For example, there is a Korean traditional wood-frame Hwangtoh building $\left(9 \times 18 \times 2.4 \mathrm{~m}^{3}\right.$, width $\mathrm{x}$ length $\mathrm{x}$ height), Ondol (Korean floor heating system) floor, $9 \times 18 \mathrm{~m}^{2}$ of Hwangtoh ceiling, three Hwangtoh walls (because the size of windows and doors were assumed to be the size of one-side wall), and air-exchange rates of 0.5 and 0.1 air changes per hour (ach). According to all surface exhalation rates of Hwangtohs in Table 1, the contribution of the Hwangtoh to indoor levels would be between 1.97 and 4.20 $\mathrm{Bq} \cdot \mathrm{m}^{-3}$ as shown in Table 4. The values are significantly less than the concentrations of 74.1 $\mathrm{Bq} \cdot \mathrm{m}^{-3}$ observed in structures built from ochre materials (Kim et al, 2002). To compare our results of the radon emanation rates from Hwangtoh materials with those of other references in Table 2, Korean Hwangtohs tested in this study belonged to the lowest group of the radon emanation among the various world soils. The radon exhalations of the samples have been found to be well below the world average value of $57.6 \mathrm{~Bq} \cdot \mathrm{m}^{-2} \cdot \mathrm{h}^{-1}$ $\left(0.016 \mathrm{~Bq} \cdot \mathrm{m}^{-2} \cdot \mathrm{s}^{-1}\right)$.

Supposing an air exchange rate of $0.1 \mathrm{ach}$, the resulting indoor concentration would be between 9.86 and $21.02 \mathrm{~Bq} \cdot \mathrm{m}^{-3}$. Hence it is concluded that these Hwangtoh materials in this study are available to use for construction purposes until due to low exhalation of radon, which is lower than the Korean radon recommendation level, $200 \mathrm{~Bq} / \mathrm{m}^{3}$. Another example can be found in the previous paper (Seo et al., 2018). 
Table 4. Indoor Radon Concentration

\begin{tabular}{cccc}
\hline Production area & $\begin{array}{c}\text { Surface exhalation rate } \\
\left(\mathrm{Bq} \cdot \mathrm{m}^{-2} \cdot \mathrm{h}^{-1}\right)\end{array}$ & $\begin{array}{c}\text { Converts in Indoor } \\
\text { Concentration } \\
\left(\mathrm{Bq} \cdot \mathrm{m}^{-3}\right), 0.5 \text { ach }\end{array}$ & $\begin{array}{c}\text { Converts in Indoor } \\
\text { Concentration } \\
\left(\mathrm{Bq} \cdot \mathrm{m}^{-3}\right), 0.1 \mathrm{ach}\end{array}$ \\
\hline \hline A Province & 1.5817 & 2.20 & 10.98 \\
B Province & 1.8230 & 2.53 & 12.65 \\
C Province & 1.4208 & 1.97 & 9.86 \\
D Province & 3.0293 & 4.20 & 21.02 \\
\hline
\end{tabular}

In this case, soil radon exhalation per unit area is $174.96 \mathrm{~Bq} \cdot \mathrm{m}^{-2} \cdot \mathrm{h}^{-1}$, which is the highest among their samples, and the resulting indoor concentration would be $1214.2 \mathrm{~Bq} \cdot \mathrm{m}^{-3}$, which is 6 times larger than the Korean radon recommendation level as mentioned earlier. Therefore, it is necessary to make up with more research by increasing the number of Hwangtoh samples considering the references mentioned above. It is also recommended that the radon exhalation rate should be measured for all building materials and a standard code for indicating radon level placed on all products.

\subsection{Half-lives of radon in Hwangtohs}

Radon concentration increments in a closed container attain a quasi-steady state, in which the radon emission from Hwangtohs and the transformation by halflives are practically equal. (Lee et al., 2018). Fig. 4 shows a relatively high radon emission from a Hwangtoh board produced by a company from $\mathrm{N}$ city in South Korea. The graph also shows the increasing range of radon concentration decreases as the half-life continues, and it maintains at an appropriate level. It is easy to identify what the tendency of radon concentration is about according to the number of half-life cycles. As a result of the board, the steady state was reached at the $5^{\text {th }}$ half-life among 9 half-lives. In case of Hwangtoh sample from $\mathrm{C}$ Province, its steady state was reached at the third half-life. In short, the board with higher radon concentration evidently required the longer time to reach the quasi-steady state in the test

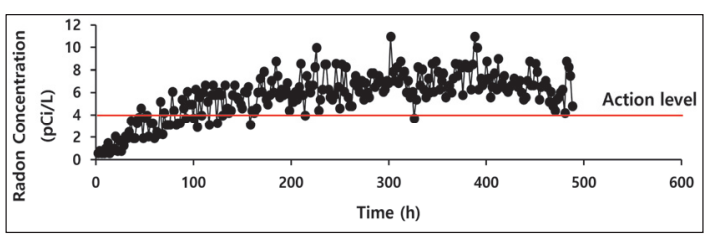

Fig. 2. Radon concentration of $\mathrm{C}$ province Hwangtoh in chamber.

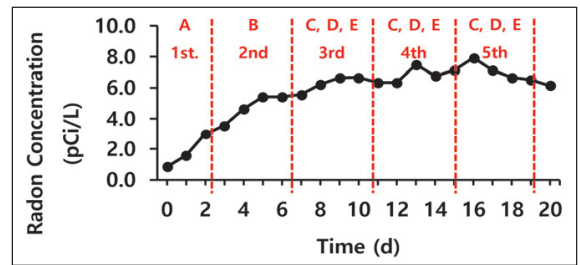

Fig. 3. Daily averages of the concentration of $\mathrm{C}$ province Hwangtoh in chamber.

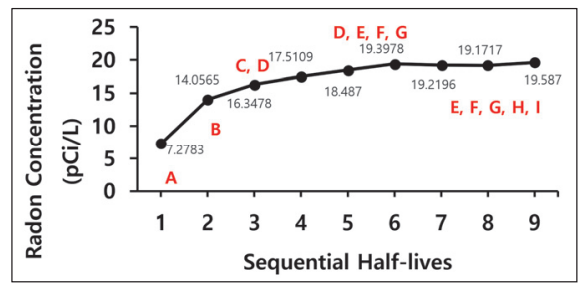

Fig. 4. Averages of sequential half-lives of commercial Hwangtoh board and group difference by Scheffe test.

environment, in other words, the number of half-life it cycled through increased from the set starting point. As mentioned earlier, the results of Fig. 2 and Fig. 3 depict radon concentrations for Hwangtoh materials in the chamber without reflecting the control's background. 
The radon concentrations of Hwangtoh materials were compared up to the fifth half-life by the CCM. The results of Table 4 were shown only for five sequential half-lives because more measurements were not necessary since the average peaks of the concentrations were attained at the forth half-life. The measurements were taken to 20 days, unlike previous papers (Lee et al., 2015; Najam et al., 2014), which noted that two or three months were needed. The statistical significance test for group difference between the number of half-lives indicated the same results whether the values were calibrated or not because there were no differences between the corrected averages and original non-corrected averages (Lee et al., 2018). As a result of the statistical processing data, all Hwangtoh materials were confirmed in the same group of the $3^{\text {rd }}, 4^{\text {th }}$ and $5^{\text {th }}$ half-lives by the Scheffe test, and one last Hwangtoh material was positioned in the different group of $4^{\text {th }}$ and $5^{\text {th }}$ half-lives. Therefore, the experiment was proceeded until the fifth half-life period as shown in Table 5 .

Table 5. Group Differences among Half-lives of Radon Exhalation from Hwangtohs

\begin{tabular}{|c|c|c|c|c|c|c|c|}
\hline $\begin{array}{c}\text { Production area / } \\
\text { Manufacturing company }\end{array}$ & $\begin{array}{c}\text { Overall Avg. } \\
\text { in chamber. }(\mathrm{pCi} / \mathrm{L}) \\
\end{array}$ & \multicolumn{2}{|c|}{$\begin{array}{c}\text { Half-live }(\text { mean } \pm \text { SD) } \\
\text { 1st } \sim 5 \text { th, T-mean }\end{array}$} & $\begin{array}{l}\text { Min } \\
\text { Max }\end{array}$ & F-test & P-Value & Group difference \\
\hline \multirow{6}{*}{ A Province } & \multirow{6}{*}{6.3} & $1^{\text {st }}$ & $2.6696 \pm 1.4340$ & \multirow{6}{*}{$\begin{array}{c}.00 \\
11.00\end{array}$} & \multirow{6}{*}{111.527} & \multirow{6}{*}{.000} & \multirow{6}{*}{$\mathrm{A}<\mathrm{B}<\mathrm{C}, \mathrm{D}, \mathrm{E}$} \\
\hline & & $2^{\text {nd }}$ & $6.1565 \pm 1.2305$ & & & & \\
\hline & & $3^{\text {rd }}$ & $7.1630 \pm 1.2565$ & & & & \\
\hline & & $4^{\text {th }}$ & $7.5283 \pm 1.5200$ & & & & \\
\hline & & $5^{\text {th }}$ & $7.7522 \pm 1.2608$ & & & & \\
\hline & & $\mathrm{T}_{\mathrm{m}}$ & $6.2539 \pm 2.3031$ & & & & \\
\hline \multirow{6}{*}{ B Province } & \multirow{6}{*}{7.2} & $1^{\text {st }}$ & $3.1696 \pm 1.7194$ & \multirow{6}{*}{$\begin{array}{c}.40 \\
12.10\end{array}$} & \multirow{6}{*}{117.810} & \multirow{6}{*}{.000} & \multirow{6}{*}{$\mathrm{A}<\mathrm{B}<\mathrm{C}, \mathrm{D}, \mathrm{E}$} \\
\hline & & $2^{\text {nd }}$ & $7.1196 \pm 1.6084$ & & & & \\
\hline & & $3^{\text {rd }}$ & $8.2239 \pm 1.2162$ & & & & \\
\hline & & $4^{\text {th }}$ & $8.7022 \pm 1.3121$ & & & & \\
\hline & & $5^{\text {th }}$ & $8.8130 \pm 1.4389$ & & & & \\
\hline & & $\mathrm{T}_{\mathrm{m}}$ & $7.2057 \pm 2.5644$ & & & & \\
\hline \multirow{6}{*}{ C Province } & \multirow{6}{*}{5.7} & $1^{\text {st }}$ & $2.6022 \pm 1.4310$ & \multirow{6}{*}{$\begin{array}{c}.60 \\
11.00\end{array}$} & \multirow{6}{*}{97.676} & \multirow{6}{*}{.000} & \multirow{6}{*}{$\mathrm{A}<\mathrm{B}<\mathrm{C}, \mathrm{D}, \mathrm{E}$} \\
\hline & & $2^{\text {nd }}$ & $5.4413 \pm 1.2710$ & & & & \\
\hline & & $3^{\text {rd }}$ & $6.4304 \pm 1.3293$ & & & & \\
\hline & & $4^{\text {th }}$ & $7.0043 \pm 1.2176$ & & & & \\
\hline & & $5^{\text {th }}$ & $7.2261 \pm 1.2073$ & & & & \\
\hline & & $\mathrm{T}_{\mathrm{m}}$ & $5.7409 \pm 2.1216$ & & & & \\
\hline \multirow{6}{*}{ D Province } & \multirow{6}{*}{11.7} & $1^{\text {st }}$ & $5.1630 \pm 1.4310$ & \multirow{6}{*}{$\begin{array}{c}.40 \\
19.00\end{array}$} & \multirow{6}{*}{175.621} & \multirow{6}{*}{.000} & \multirow{6}{*}{$\mathrm{A}<\mathrm{B}<\mathrm{C}<\mathrm{D}, \mathrm{E}$} \\
\hline & & $2^{\text {nd }}$ & $5.4413 \pm 1.6834$ & & & & \\
\hline & & $3^{\text {rd }}$ & $13.278 \pm 1.8693$ & & & & \\
\hline & & $4^{\text {th }}$ & $14.689 \pm 2.0253$ & & & & \\
\hline & & $5^{\text {th }}$ & $14.854 \pm 1.8772$ & & & & \\
\hline & & $\mathrm{T}_{\mathrm{m}}$ & $11.672 \pm 4.1794$ & & & & \\
\hline
\end{tabular}




\section{CONCLUSION}

The CCM conducted by a CRM has been used to determine radon exhalation rates from building materials. In this study, four different Hwangtohs of mass market brands were selected considering accessibility, convenience, and locations, and were compared for radon exhalation rates based on four different regional features of raw materials in South Korea. The radon mass exhalation rates of all the samples were distributed from 0.0398 to $0.0848 \mathrm{~Bq} \cdot \mathrm{kg}^{-1} \cdot \mathrm{h}^{-1}$, and the surface exhalation rates resulted in the 1.4208 to $3.0293 \mathrm{~Bq} \cdot \mathrm{m}^{2} \cdot \mathrm{h}^{-1}$ range. Even though significant differences were found among Hwangtoh materials according to the production region of raw materials, the Korean Hwangtoh materials are satisfied to use for the construction purposes due to both low radon exhalations below the Korean radon recommendation level $200 \mathrm{~Bq} \cdot \mathrm{m}^{-3}$ and the WHO's action level, 100 $\mathrm{Bq} / \mathrm{m}^{3}$. To reach a quasi-steady state in case of an environment with high radon concentration, the number of half-life cycles increases from a set starting point. The more study of the relationship between radon and Hwangtoh is still necessary to corroborate with more research by increasing the number of Hwangtoh samples, considering the other references reported high radon exhalation rates. In addition, it is highly recommended that the radon exhalation rates should be measured for all building materials for human health before the materials were used.

\section{REFERENCES}

Awhida, A., Ujic, P., Vukanac, I., Durasevic, M., Kandic, A., Celikovic, I., Loncar, B., Kolarz, P. 2016. Novel method of measurement of radon exhalation from building materials. Journal of Environmental Radioactivity 164: 337-343.

Bala, P., Kumar, V., Mehra, R. 2017. Measurement of radon exhalation rate in various building materials and soil samples. Journal of Earth System Science 126(31): 1-8.

Chen, J., Rahman, N.M., Abu Atiya, I. 2010. Radon exhalation from building materials for decorative use. Journal of Environmental Radioactivity 101(4): 317-22.

Choi, W.S., Yang, S.O., Lee, J.H., Choi, E.J., Kim, Y.H., Yang, J.Y., Park, M.J. 2020. Profiling patterns of volatile organic compounds in intact, senescent, and litter red pine. Jouranl of the Korean Wood Science and Technology 48(5): 591-607.

Elliot, T., Bonotto, D.M., Andrews, J.N. 2014. Dissolved uranium, radium and radon evolution in the continental intercalaire aquifer, algeria and tunisia. Journal of Environmental Radioactivity 137: $150-162$.

Environmental Protection Agency (EPA) 2012. A citizen's guide to radon. The guide to protecting yourself and your family from radon. pp. 1-16.

Faheem, M., Matiullah 2008. Radon exhalation and its dependence on moisture content from samples of soil and building materials. Radiation Measurements 43(8): 1458-1462.

Gundersen, L.C.S., Schumann, R.R. 1996. Mapping the radon potential of the united states: Examples from the appalachians. Montreal, Canada, Proceedings of the 1995 6th International Symposium on the Natural Radiation Environment, NRE, 22(1): 829-837.

Han, H.J., Lee, S.E., Yang, S.M., Chio, C., Kang, S.G. 2019. Evaluation of formaldehyde emission from wood-based panels using accelerated collection method. Journal of the Korean Wood Science and Technology 47(2): 129-144.

Hwang, J., Lee, H. 2010. The applications and mineral compositions of residual soils distributed in south korea(asian clay special paper). Clay Science 14(6): 253-262.

Hwang, J., Park, H., Yang, K., Lee, H. 2002. Mineralogy 
and chemical properties according to particle size separation of hwangto (reddish residual soil) used in feeding of cattle. Journal of the Mineralogical Society of Korea 15(1): 33-43.

International Agency for Research on Cancer (IARC) 1988. Man-made mineral fibres and radon. IARC monographs on the evaluation of carcinogenic risks to humans, 43 .

International Commision on Radiological Protection (ICRP) 1993. Protection against radon-222 at home and at work. ICRP Publication 65. Ann. ICRP, 23(2): 1-45.

Ingersoll, J.G. 1983. A survey of radionuclide contents and radon emanation rates in building materials used in the u.S. Health Physics 45(2): 363-368.

Jang, J.H., Lee, M., Lee, S.M., Park, S.B. 2017. Formaldehyde emission of building materials and effection of carbonized board on their reduction. Journal of the Korean Wood Science and Technology 45(3): 327-334.

Jang, J.H., Lee, M., Kang, E.C., Lee, S.M. 2017. Characteristics of low density fiberboards bonded with different adhesives for thermal insulation(II). Journal of Korean Wood Science and Technology 45(5): 580-587.

Jeong, G., Kim, S. 1990. Iron oxide minerals in the sancheong kaolin deposits. Journal of The Mineralogical Society of Korea 3(2): 79-88.

Kim, I., Seo, S., Kang, C. 2000. General properties and ferric oxide content of hwangtoh (yellow ochre). Journal of Korean Pharmaceutical Sciences 30(3): 219-222.

Kim, J.S. 2018. Indoor radon levels and effective dose estimation in learning and common living space of university. J. Korean Soc. Radiol. 12(3): 329-333.

Kim, K., Kim, S., Park, M., Kim, H., Park, J. 2010. Characteristics of a reddish residual soil (hwangtoh) finishing material with water-soluble adhesive for residential building. Construction and Building
Materials 24(8): 1542-1546.

Kim, C., Noh, J., Park, S., Park, S., Park, H., Lee, D., Lee, J., Lee, H., Jang, B., Jin, H., Choi, S., Kim, O., Park, S., Lee, M., Lee, S., Cho, E., Choi, S., Choi, Y., Choi, J., Han, H. 2002. Assessment of radiation risk for korean population and nationwide indoor radon survey in korea: Nationwide survey of indoor radon level in korea, Korea Institute of Nuclear Safety (KINS), 3(1): 100-151.

Korean Ministry of Environment (KME) 2016. Indoor air quality control in public-use facilities, etc. Act. 2003. No. 6911.

Lee, C., Jung, S., Lee, D., Kim, Y., Lee, D., Cho, Y., Jin, Y. 2015. Investigation of radon emanation of domestic building materials. Journal of Odor and Indoor Environment 14(1): 50-56.

Lee, J., Choi, G., Kang, S. 2018. Radon exhalation from five wood species. Journal of the Korean Wood Science and Technology 46(6): 735-747.

Lee, M., Park, S.B., Lee, S.M., Lee, H.Y., Kil, D.H. 2014. Emisson characteristics of volatile organic compounds by humidifer with using hinoki cypress extracts. Journal of the Korean Wood Science and Technology 42(6): 747-757.

Lubin, J.H., Boice, J.D., Jr. 1997. Lung cancer risk from residential radon: Meta-analysis of eight epidemiologic studies. Journal of the National Cancer Institute 89(1): 49-57.

Lubin, J.H., Boice, J.D., Jr., Edling, C., Hornung, R. W., Howe, G.R., Kunz, E., Kusiak, R.A., Morrison, H.I., Radford, E.P., Samet, J.M., et al. 1995. Lung cancer in radon-exposed miners and estimation of risk from indoor exposure. Journal of the National Cancer Institute 87(11): 817-827.

Mahur, A.K., Kumar, R., Sengupta, D., Prasad, R. 2009. Radon exhalation rate in chhatrapur beach sand samples of high background radiation area and estimation of its radiological implications. Indian Journal of Physics 83(7): 1011-1018. 
Mun, S.W., Kang, Y.S., Park, J.H., Han, M.S., Jeong, H.Y. 2019. A study on the making properties of natural pigments based on substance characteristics for hwangto in korea. Journal of Conservation Science 35(6): 600-611.

Najam, L., Tawfiq, N., Mahmood, R. 2014. Radon concentration in some building materials in iraq using cr-39 track detector. International Journal of Physics 1(3): 73-76.

Nazaroff, W.W., Nero, A.V. 1988. Radon and its decay products in indoor air. New York, NY (US); John Wiley and Sons, Incorporated, United States.

Neidherr, D., Audi, G., Beck, D., Blaum, K., Bohm, C., Breitenfeldt, M., Cakirli, R.B., Casten, R.F., George, S., Herfurth, F., Herlert, A., Kellerbauer, A., Kowalska, M., Lunney, D., Minaya-Ramirez, E., Naimi, S., Noah, E., Penescu, L., Rosenbusch, M., Schwarz, S., Schweikhard, L., Stora, T. 2009. Discovery of 229rn and the structure of the heaviest $\mathrm{rn}$ and ra isotopes from penning-trap mass measurements. Physical Review Letters 102(11): 1-5.

Oufni, L. 2003. Determination of the radon diffusion coefficient and radon exhalation rate in moroccan quaternary samples using the ssntd technique. Journal of Radioanalytical and Nuclear Chemistry 256(3): 581-586.

Parajuli, P., Thapa, D., Shah, B. 2015. Study of radon exhalation rate in soil samples of kathmandu valley using passive detector lr115. International Journal of Chemical and Physical Sciences 4(4): 30-39.

Park, H.J., Jo, S.E. 2020. Evaluation of physical, mechanical properties and pollutant emissions of wood-magnesium laminated board(WML Board) for interior finishing materials. Journal of the Korean Wood Science and Technology 48(1): 86-94.

Petropoulos, N.P., Anagnostakis, M.J., Simopoulos, S.E. 2001. Building materials radon exhalation rate: Erricca intercomparison exercise results. Science of the Total Environment 272(1-3): 109-118.
Rhie, J., Choi, K. 2005. Coloration of synthetic fiber fabrics with loess(i). Korean Journal of Human Ecology 8(1): 19-24.

Seo, J., Nirwono, M.M., Park, S.J., Lee, S.H. 2018. Standard measurement procedure for soil radon exhalation rate and its uncertainty. Journal of Radiation Protection and Research 43(1): 29-38.

Seok, J., Jun, S. 2009. Control of redtide microbes with hydrogen peroxide and yellow loess. Journal of Korean Society of Water and Wastewater 23(4): 491-497.

Shin, G., Choo, Y., Kim, K., Ryu, H., Lee, S. 2011. Evaluation of lanthanum(iii): loess compositeas an adsorbent for phosphate removal. Journal of Korean Society of Environmental Engineers 33(2): 143-148.

Shweikani, R., Hushari, M. 2005. The correlations between radon in soil gas and its exhalation and concentration in air in the southern part of syria. Radiation Measurements 40(2-6): 699-703.

Singh, S., Kumar, M., Mahajan, R.K. 2005. The study of indoor radon in dwellings of bathinda district, punjab, india and its correlation with uranium and radon exhalation rate in soil. Radiation Measurements 39(5): 535-542.

United Nations Scientific Committee on the Effects of Atomic Radiation (UNSCEAR) 1969. Report of the united nations scientific committee on the effects of atomic radiation.

United Nations Scientific Committee on the Effects of Atomic Radiation (UNSCEAR) 2000. Source, effects and risk of ionizing radiation.

Webb, G.A.M. 1992. Exposure to radon. Radiation Protection Dosimetry 42(3): 191-195.

Yoo, J., Lee, K., Seo, S., Kim, S., Lee, J. 2019. Comparison of indoor radon concentrations in areas of jeollabuk-do province. Journal of Environmental Health Sciences 45(6): 658-667.

World Health Organization (WHO) 2009. WHO handbook on indoor radon: A public health perspective. 1(1.1): 7-13. 